Revista de

Contabilidade e

Organizações

www.rco.usp.br
DOI: http://dx.doi.org/10.11606/rco.v10i28.124789
Journal of

Accounting and

Organizations

www.rco.usp.br

\title{
Percepção dos professores de contabilidade quanto aos espaços formativos para o ofício da docência no Brasil
}

\author{
Raíssa Silveira de Farias ${ }^{\mathrm{a}}$; Adriana Maria Procópio de Araujo ${ }^{\mathrm{a}}$ \\ ${ }^{a}$ Universidade de São Paulo
}

\section{Informações do Artigo}

Histórico do Artigo

Recebido: 21 de novembro de 2016

Aceito: 11 de janeiro de 2017

Palavras chave:

Formação docente.

Contabilidade.

Ensino.

Espaços formativos.

\begin{abstract}
Resumo
O objetivo do estudo foi analisar a percepção dos docentes, mestres e doutores em contabilidade no Brasil, a respeito dos espaços formativos para a docência propostos por Swain \& Stout (2000): Programa de Pós-graduação, Instituição de Ensino Superior (IES) e esforço individual. Utilizou-se como estratégia de pesquisa um levantamento, com dados coletados por meio de questionário online, desenvolvido, validado e autorizado por Swain \& Stout (2000). No total, foram obtidos 425 questionários de 328 mestres e 97 doutores, sendo 378 docentes representando todos os Estados Federativos do Brasil. O principal resultado do estudo indicou que, a responsabilidade pela formação para a docência, tanto do Programa de Pós-graduação quanto das IES é maior do que a formação proporcionada por esses espaços formativos. Como contribuição, tem-se a perspectiva de debate sobre como os programas de pósgraduação estão formando seus docentes.
\end{abstract}

Copyright (C) 2016 FEA-RP/USP. Todos os direitos reservados

\section{INTRODUÇÃO}

O ambiente educacional é palco de diversas transformações, por meio dos avanços da tecnologia e da ciência, os quais influenciam diretamente os meios de acesso à informação e ao conhecimento. Araujo e Mello (2014) observam que é nesse ambiente que há a maior integração entre a transferência de conhecimento e sua consolidação, principalmente em relação à formação profissional, intelectual e social do indivíduo.

O desempenho dos docentes no processo de formação do profissional contábil é objeto de estudo de vários pesquisadores. Vendruscolo e Behar (2014) ressaltam que o papel do professor na formação dos futuros profissionais exige conhecimento teórico, pedagogia e experiência profissional. Andere e Araujo (2008) apontam ser necessário ao docente de Contabilidade conhecimentos teóricos, estruturais, didáticos e pedagógicos; além dos conhecimentos e das habilidades técnicas exigidas pela profissão de contador. A formação de professores para o ensino superior vem ganhando ênfase no cenário mundial, em decorrência da importância do ensino nos cursos de graduação e o frequente despreparo dos docentes para essa atividade (Almeida \& Pimenta, 2014).

Alguns estudos tratam deste assunto no âmbito nacional e internacional: Boyle, Carpenter, Hermanson \& Mero, 2015; Nganga, Botinha, Miranda \& Leal, 2014; Brightman e Nargundkar, 2013; Slomski, Lames, Megliorini \& Lames, 2013; Andere \& Araujo, 2008; Slomski, 2007; Swain \& Stout, 2000, entre outros. As discussões são voltadas para o profissionalismo na docência; a genealogia dos saberes da prática docente; a importância do contato com práticas exercidas no mercado profissional; e a relevância dos conhecimentos didático-pedagógicos no processo de ensino-aprendizagem (Miranda, Casa Nova \& Cornacchione Jr., 2014; Slomski, Lames, Megliorini \& Lames, 2013; Slomski, 2007).

As fontes ou espaços formativos deste conhecimento são identificadas na literatura, tanto da área da educação, como da contábil (Shulman, 1987; Swain \& Stout, 2000; Tardif \& Raymond, 2000; Slomski, 2009, Marshall, Dombrowski, Garner \& Smith, 2010, Tardif, 2012, Slomski, Lames, Megliorini \& Lames, 2013,

Autor Correspondente: Tel (16) 3315-0573

E-mail: farias.issa@gmail.com (R. S. Farias); amprocop@usp.br (A. M. P. Araujo)

FEARP - USP - Avenida dos Bandeirantes no 3900 - Sala 4 - Bloco A - Monte Alegre - 14040900 - Ribeirão Preto, SP - Brasil 
Brightman \& Nargundkar, 2013). O entendimento de que os Programas de Pós-graduação e as Instituições de Ensino Superior (local de trabalho dos docentes) são espaços de formação continuada para o ofício da docência existe, no entanto, os métodos utilizados por esses espaços formativos, a responsabilidade e a real formação proporcionada não são foco de muitos estudos no âmbito da ciência contábil, principalmente, analisados de forma conjunta (Laffin, 2008, 2012; Slomski, et al, 2013).

No Brasil, um espaço formativo para formação docente é a pós-graduação stricto sensu, uma vez que a preparação para o exercício da docência superior far-se-á, prioritariamente, neste nível de ensino, conforme determina a Lei de Diretrizes e Bases do Ensino Superior (LDB), Lei nº 9.394/96. Assim, é razoável que os cursos de Pós-graduação em Contabilidade ofereçam componentes curriculares que possibilitem aos discentes o acesso aos saberes pedagógicos, importantes ao preparo para a sua atuação na docência (Nganga, Botinha, Miranda \& Leal, 2016).

Outro espaço formativo para a formação dos docentes do ensino superior, é a Instituição de Ensino Superior (IES), uma vez que são consideradas espaço de formação continuada ao seu corpo docente, por meio de diálogo e reflexão sobre a teoria e a prática necessárias ao ofício da profissão docente. Entende-se que a IES é um terreno fértil à qualificação não somente daqueles que nela estudam, mas também para os que nela ensinam (Rivas, Conte \& Aguilar, 2007). Assim, o estudo objetivou a análise da percepção dos professores, mestres e doutores em contabilidade, no Brasil, no que tange aos métodos utilizados pelos espaços formativos propostos por Swain e Stout (2000): Programas de Pós-graduação, IES e interesse próprio na busca de conhecimento, para a sua formação para a docência.

\section{PLATAFORMA TEÓRICA}

\subsection{Espaços formativos para a docência}

Toda profissão para que se consolide como tal necessita de saberes formalizados e sistematizados. Tardif (2012) defende que todo saber implica em um processo de aprendizagem e de formação; e, quanto mais desenvolvido, formalizado e sistematizado é um saber, mais longo e complexo se torna o processo de aprendizagem.

As formações inicial e continuada podem ser consideradas como dois estágios principais desse processo, sendo o estágio inicial, aquele que ocorre quando se prepara para o ingresso na profissão, em cursos de licenciatura, e o estágio da formação continuada ao longo de sua carreira profissional, por meio de atualizações periódicas, em cursos de Pós-graduação e em cursos de formação promovidos pelas Instituições de Ensino Superior, por exemplo.

A formação inicial, no que tange aos conhecimentos necessários à docência, para professores do ensino superior, cujo saber disciplinar base foi adquirido em cursos de bacharelado, devem ser desenvolvidos em programas de Pós-graduação stricto sensu, conforme apontado pela Lei de Diretrizes e Bases da Educação Nacional (LDBEN), Lei 9.394 de 1996. A Capes (2015) corrobora com a LDBEN, quando justifica a necessidade do oferecimento de mestrados e doutorados eficientes e de alta qualidade, em três objetivos, sendo o de maior interesse nesse estudo o que diz: (i) formação de professorado competente que possa atender a demanda no ensino básico e superior garantindo, ao mesmo tempo, a constante melhoria da qualidade (...).

Para tanto, alguns métodos de formação são necessários. Shulman (1987) defende que há pelo menos quatro métodos principais para a base do conhecimento sobre o ensino: (1) disciplinas acadêmicas; (2) materiais e configurações do processo educativo institucionalizado (por exemplo: currículos, livros didáticos, organizações escolares e a estrutura da profissão docente); (3) pesquisas acadêmicas sobre escolaridade, organizações sociais, aprendizagem humana, ensino e desenvolvimento, e os outros fenômenos sociais e culturais que afetam o que os professores podem fazer; e (4) a sabedoria da própria prática.

Em um estudo realizado por Lapini (2012) foi analisado de que forma os programas de Pós-graduação stricto sensu em Ciências Contábeis formam professores. Baseada em 25 cursos que oferecem doutorado, mestrado acadêmico e mestrado profissional, a autora apontou que três são os métodos utilizados pelos cursos para a formação de professores: disciplina com preparação pedagógica, prática docente supervisionada e atividades complementares, e que seis programas formam docentes. A autora concluiu ainda que, a partir dos dados obtidos e das análises realizadas, o processo de educação continuada para o professor de contabilidade não foi detectado, apontando que os cursos de Pós-graduação em Contabilidade, no Brasil, não preparam o aluno para a docência. 
Quanto às disciplinas apontadas por Lapini (2012), verifica-se que são poucas as que abordam questões relacionadas aos aspectos didático-pedagógicos da docência. Em um estudo realizado por Nganga et al. (2016) com o objetivo de identificar quais são os componentes curriculares de formação pedagógica sistematizada presentes nos 18 programas de Pós-graduação stricto sensu em Ciências Contábeis, no Brasil, os autores encontraram um baixo número de disciplinas relativas à formação de professores oferecidas pelos cursos de mestrado e doutorado em Ciências Contábeis, uma vez que do total de disciplinas oferecidas pelos programas, apenas 14 são ligadas à formação docente e, quando tais disciplinas são oferecidas, essas são, em geral, de caráter optativo (apenas duas são obrigatórias) e carga horária igual ou inferior a 60 horas.

Outro método de formação para docência utilizado pelos Programas de Pós-graduação são os Estágios, o qual foi estabelecido como obrigatório aos alunos bolsistas CAPES/DS, e opcional aos demais, pelo Ministério da Educação, juntamente com a CAPES, por meio da Portaria MEC/CAPES nº 76/2010. Conforme a Portaria, a duração mínima do Estágio Docência para os programas de mestrado será de um semestre e a máxima, de dois semestres. Já para os programas de doutorado, a duração mínima será de dois semestres e máxima, de três semestres, cuja carga horária máxima deverá ser de quatro horas semanais. No entanto, Nganga et al. (2016) constatou grande heterogeneidade na forma como tais atividades, relacionados à formação prática para a docência, mais especificamente ao Estágio Docência, estão sendo desenvolvidas nos Programas de Pós-graduação stricto sensu, em Ciências Contábeis.

Quanto à formação continuada para os docentes do ensino superior, acredita-se ser papel da IES fornecêla, uma vez que pode ser entendida como um terreno fértil às colaborações efetivas e à qualificação não somente daqueles que nela estudam, mas também para os que nela ensinam (RIVAS, CONTE \& AGUILAR, 2007). Vários são os autores que defendem esta necessidade: BAQUEIRO (2007), MELO \& CORDEIRO (2008), PIMENTA \& ANASTASIOU (2011), SOUZA (2013), entre outros.

Algumas iniciativas de instituições universitárias vêm sendo apontadas na literatura, como a oferta de cursos de Pós-graduação lato sensu de Metodologia do Ensino Superior e Didática do Ensino Superior, com carga horária de pelo menos 360 horas, nos quais incluem disciplinas como Psicologia da Aprendizagem, Planejamento de Ensino, Didática e Metodologia de Ensino (GIL, 2006).

Outras propostas, ainda isoladas, de cursos de Especialização em Pedagogia Universitária, vêm sendo realizadas com o objetivo de fornecer formação continuada em serviço dos professores da Instituição, oportunizando momentos de reflexão sobre as identidades, modelos e dispositivos de formação de professores para atuar no contexto contemporâneo do Ensino Superior, além de possibilitar, dialeticamente, ao professor o desenvolvimento das dimensões epistemológica, pedagógica e política, levando em conta a sua experiência como profissional de uma determinada área (BAQUEIRO, 2007).

Assim, as formações continuadas didático-pedagógicas se tornam um dos caminhos para que os docentes do ensino superior possam construir suas identidades profissionais e assim, refletirem sobre a finalidade da docência universitária; pois, são nessas formações que teorias, discussões e sínteses (referentes à realidade enfrentada cotidianamente nas salas de aula) são confrontadas e submetidas à reflexão coletiva (SOUZA, 2013).

\subsection{Estudos anteriores em contabilidade}

Após discorrer sobre os espaços formativos para a formação do professor do ensino superior, neste tópico serão expostos alguns estudos empíricos sobre essa formação, do ponto de vista de pós-graduandos, docentes e coordenadores dos programas de pós-graduação em contabilidade, a partir de diversos focos.

Miranda (2010) investigou a formação pedagógica oferecida pelos Programas de Pós-graduação stricto sensu em Contabilidade, a partir de disciplinas relacionadas ao ensino. O autor verificou que entre os 18 Programas de Mestrado e os três de Doutorado existentes no Brasil, em 2008, em apenas dois (Mestrados) existia a obrigatoriedade de se cursar disciplinas didático-pedagógicas, os quais apresentam as menores cargas horárias.

Andere e Araujo (2008), analisaram a formação docente a partir da percepção de 12 coordenadores de Programas de Pós-graduação (Stricto Sensu) na área contábil e 208 discentes. Os resultados apontaram que os programas de Pós-graduação, na percepção dos discentes, estão direcionados à formação dos futuros docentes, no entanto na percepção dos coordenadores de pós, a formação direciona-se para a formação de pesquisadores.

Slomski (2009) demonstrou em um estudo efetuado com 184 professores, atuantes em diversas IES no Brasil, que segundo suas percepções, em vista das limitações quanto à formação profissional para o magistério, 
era a própria experiência na profissão, na sala de aula, na universidade, e a experiência dos pares que vinham estruturando e dando sentido à prática pedagógica dos professores de Ciências Contábeis.

Swain e Stout (2000) desenvolveram um estudo com recém-doutores em Contabilidade nos EUA, e concluíram que, no geral, a maioria dos docentes não está adequadamente preparado para ensinar, e que a maioria das habilidades que refletem esforços para desenvolver as competências didático-pedagógicas, estudadas pelos autores, foram desenvolvidas a partir dos esforços individuais, ao invés dos programas de doutorado e das instituições de ensino, na qual atuam como docentes.

Brightman e Nargundkar (2013) sugerem que a formação de professores deveria: (1) ser exigida de todos os alunos de doutorado (com exceções feitas, se alguém tem um histórico comprovado de excelência no ensino); (2) incluir o estudo da literatura pedagógica; (3) abranger gestão de sala de aula, habilidades de apresentação, motivação dos alunos, organização de curso, estratégias ativas de aprendizagem, tecnologia, avaliação dos alunos; (4) exigir observação do ensino pelos colegas ou professores com feedback construtivo; e (5) ajudar os alunos a desenvolver uma filosofia de ensino. Pois, dessa forma, segundo os autores, estudantes de doutorado e instituições de ensino se beneficiariam, uma vez que, formados para o ensino, os professores (1) seriam um produto melhor; (2) evitariam as frustrações de ensino comum; (3) teriam mais tempo para fazer pesquisa; e (4) aproveitariam a experiência de sala de aula em conjunto com seus alunos.

Em síntese, os estudos discutidos apresentaram reflexões sobre a formação de professores para o exercício da docência no ensino superior. Neles, fica claro o entendimento de que os Programas de Pós-graduação e as Instituições de Ensino Superior são espaços de formação continuada para o ofício da docência. No entanto, os métodos utilizados por esses espaços formativos, a responsabilidade e a real formação proporcionada não são foco de muitos estudos, principalmente, analisados de forma conjunta, assim, na presente pesquisa, pretendem-explorar esses aspectos.

\section{MÉTODOS}

O objetivo do estudo foi analisar a percepção dos docentes, mestres e doutores em contabilidade no Brasil, a respeito dos espaços formativos para a docência propostos por Swain \& Stout (2000): Programa de Pósgraduação, Instituição de Ensino Superior (IES) e esforço individual.

O público-alvo da pesquisa foram os professores, mestres e doutores titulados em contabilidade no Brasil. Foram identificados 21 Programas de Pós-graduação em Contabilidade, dos quais, até agosto de 2015, 16 haviam titulado mestres, e dos 10 cursos de doutorado, quatro haviam titulado doutores, totalizando um universo de 324 doutores e 3.061 mestres. Para a composição da amostra foi realizado um corte a partir de 2004, pela data da revisão do projeto de currículo para os cursos de Ciências Contábeis, proposto pelo International Standards of Accounting and Reporting (ISAR). Foram selecionados os titulados mestres e doutores de 2004 a 2015, correspondendo a 2.301 mestres e 185 doutores.

O instrumento de coleta dos dados utilizado foi parte de um questionário desenvolvido, validado e autorizado por Swain e Stout (2000), composto por duas partes: na primeira os titulados responderam com informações pessoais, e na segunda, proveram informações da presença de alguns métodos de formação associados ao desenvolvimento de habilidades de ensino. Essas questões foram agrupadas por fonte: Programa de Pósgraduação, IES na qual atua e buscado a partir de interesse pessoal. Os métodos utilizados pelo Programa de Pósgraduação e pela IES foram ainda classificados como diretos, indiretos e na prática, conforme sugerido por Swain e Stout (2000) em seu estudo.

Para a coleta das respostas dos questionários, foi utilizado o Método do Desenho Total (Total Design Method - TDM), com o objetivo de aumentar a taxa de resposta (DILLMAN, 2007). O instrumento foi disponibilizado no Google drive, plataforma de armazenamento e sincronização de arquivos em nuvem, no período de 17 de março a 05 de maio de 2016. No total, foram obtidos 425 questionários válidos de 328 mestres e 97 doutores, sendo 378 docentes. Os dados foram analisados utilizando-se da análise descritiva, de posição de tendência central, moda, para identificar onde se localiza a maior frequência da variável entre os valores observados, técnica recomendada para dados em escala de medida ordinal, em categorias discretas, como dados em escala likert; bem como do teste de Wilcoxon, utilizado para comparar a percepção dos respondentes quanto à responsabilidade de cada espaço formativo na formação para a docência e o real efeito desses espaços na formação desses. 


\section{ANÁLISE DOS RESULTADOS}

\subsection{Caracterização dos respondentes}

A amostra do estudo foi composta em sua maioria pelo gênero feminino (62,59\%); com idade entre 31 e 50 anos (69,88\%); que atuam na docência há mais de sete anos (61,90\%) em IES pública (46,12\%). Cabe ressaltar que $47(11,06 \%)$ respondentes não atuam na docência e, portanto, não serão considerados em algumas análises. Quanto à participação dos Programas de Pós-graduação, 20,71\% titulou-se na Universidade de São Paulo, mas todos os demais programas estão representados na amostra.

No quesito tempo de docência, 59,79\% encontra-se entre 7 e 25 anos de docência, período no qual Huberman (2000), aponta como sendo o da "diversificação" ou do "questionamento", considerada como uma fase "crítica" pelo autor, uma vez que o professor começa a analisar todas as possibilidades de sua carreira, ou seja, questiona-se a respeito de suas escolhas.

\subsection{Análise descritiva}

O objetivo desse tópico foi identificar se houve formação para a docência, a partir da análise dos métodos de ensino possíveis de terem sido utilizados pelos Programas de Pós-graduação, pelas IES e na busca de formação a partir de interesse próprio. Os dois primeiros espaços formativos foram analisados sob três aspectos de formação: direta, prática e indireta.

\subsubsection{Formação pelo Programa de Pós-graduação}

Foi solicitado aos respondentes que marcassem quais métodos foram utilizados em suas formações, no mestrado e no doutorado, e a ordem de importância em suas percepções, conforme Tabela 1.

Tabela 1. Métodos diretos de ensino pelo Programa de Pós-graduação

\begin{tabular}{lccccccc}
\hline & $\mathbf{1}$ & $\mathbf{2}$ & $\mathbf{3}$ & $\mathbf{4}$ & $\mathbf{5}$ & $\mathbf{6}$ & Não utilizado \\
\hline Disciplina & 245 & 43 & 30 & 27 & 27 & 42 & 11 \\
Workshop & 28 & 56 & 63 & 64 & 59 & 49 & 106 \\
Simpósio & 34 & 54 & 61 & 54 & 76 & 52 & 94 \\
Leituras & 129 & 127 & 48 & 26 & 33 & 54 & 08 \\
Grupos discussão & 87 & 71 & 89 & 55 & 41 & 38 & 44 \\
Projetos & 53 & 64 & 64 & 79 & 45 & 56 & 64 \\
\hline
\end{tabular}

Fonte: dados da pesquisa.

Com a análise da frequência das respostas, todos os métodos foram assinalados como sendo empregados pelos Programas de Pós-graduação, sendo a "disciplina" e as "leituras", voltadas para a formação docente, as mais utilizadas e as apontadas como mais importantes. No entanto, ressalta-se que nem todos os Programas de Pósgraduação utilizaram todos os métodos analisados.

Em relação ao quão suficientes esses métodos foram para a formação didático-pedagógica dos mestres e doutores, questionou-se quão preparados eles se sentem para suas atividades de ensino, a partir dos métodos diretos (Tabela 1) de formação utilizados pela Pós-graduação. O Gráfico 1 ilustra os resultados. 


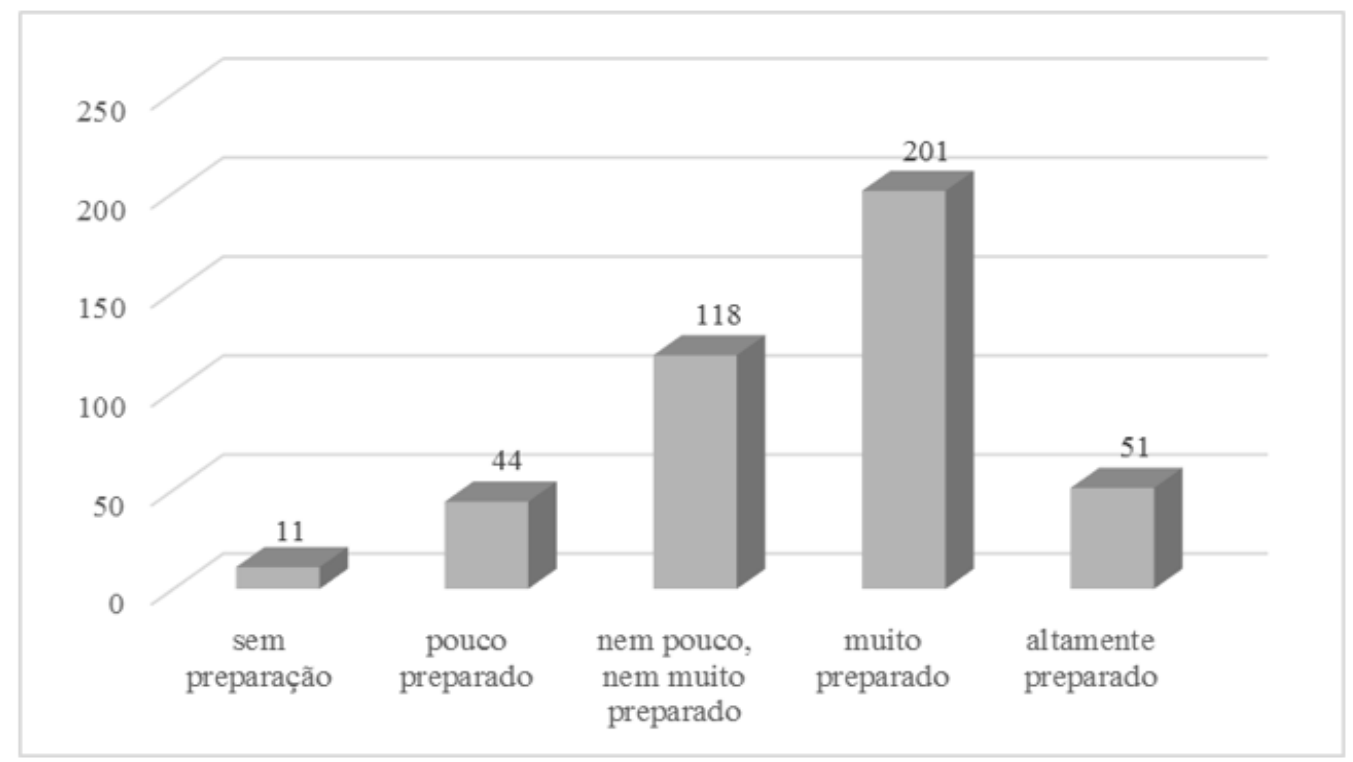

Gráfico 1. Preparação para a docência na Pós-graduação

Fonte: dados da pesquisa.

Quanto às disciplinas, Lapini (2012) aponta que são poucas as que abordam questões relacionadas aos aspectos didático-pedagógicos da docência. Em um estudo realizado por Nganga et al. (2016) com o objetivo de identificar quais os componentes curriculares de formação pedagógica presentes nos 18 programas de Pósgraduação stricto sensu em Ciências Contábeis, no Brasil, os autores encontraram um baixo número de disciplinas relativas à formação de professores oferecidas por esses cursos, uma vez que do total de disciplinas oferecidas pelos programas, apenas 14 são ligadas à formação docente e, quando tais disciplinas são oferecidas, essas são, em geral, de caráter optativo (apenas duas são obrigatórias) e com carga horária igual ou inferior a 60 horas.

Na formação prática proporcionada pela Pós-graduação, esse estudo considerou o que se denominada por Estágio Docência, o qual foi estabelecido como obrigatório aos alunos bolsistas CAPES/DS, e opcional aos demais, pelo Ministério da Educação, juntamente com a CAPES, por meio da Portaria MEC/CAPES nº 76/2010. Relacionado a esta formação, os respondentes foram questionados se: (1) ministraram disciplinas; (2) auxiliaram algum professor; (3) apresentaram algum workshop, ao longo do curso de mestrado e doutorado; e se, após essas possibilidades de contato com a docência sentem-se mais preparados para as atividades de ensino (Tabela 2).

Tabela 2. Métodos de formação prática

\begin{tabular}{lccccccc}
\hline & $\mathbf{0}$ & $\mathbf{1}$ & $\mathbf{2}$ & $\mathbf{3}$ & $\mathbf{4}$ & $\mathbf{5}$ & $\mathbf{+ 6}$ \\
\hline Número de disciplinas ministradas durante a Pós-graduação & 160 & 122 & 41 & 29 & 12 & 28 & 33 \\
Número de professores auxiliados & 148 & 129 & 53 & 26 & 19 & 27 & 23 \\
Número de workshops apresentados & 159 & 90 & 37 & 30 & 18 & 35 & 56 \\
\hline
\end{tabular}

Fonte: dados da pesquisa.

A maioria dos respondentes não ministrou disciplina durante a Pós-graduação, bem como não auxiliou um professor nas atividades para a docência, e não apresentou workshop. Tal resultado pode ser corroborado com a questão seguinte sobre quão preparados se sentem para as atividades de ensino, a partir da formação prática recebida no Programa de Pós-graduação, uma vez que a maioria dos respondentes apontaram sentir-se nem pouco, nem muito preparado $(48,71 \%)$.

Esse resultado pode servir de alerta aos Programas de Pós-Graduação sobre a efetividade da execução do Estágio Docência, considerado obrigatório aos alunos bolsistas CAPES/DS. Nganga, et al. (2016) constataram heterogeneidade na forma como tais atividades, relacionados à formação prática para a docência, mais especificamente ao Estágio Docência, estão sendo desenvolvidas nos Programas de Pós-graduação stricto sensu, em Ciências Contábeis, uma vez que há diferentes nomenclaturas, diferentes cargas-horárias dedicadas à prática, 
bem como obrigatoriedade diversa.

Quanto à formação indireta proporcionada pelo Programa de Pós-graduação, entende-se que alguns professores podem sentir que parte da formação docente acontece por meio da observação e das discussões com outros professores. Nesse sentido, foi questionado aos respondentes (1) quão contribuiu ter observado algum professor, no Programa de Pós-graduação; e (2) quão contribuiu as orientações e discussões com professores da Pós-graduação, ambos para a formação docente. Para as duas perguntas, a maioria das respostas obtidas apontou ter contribuído muito para a formação docente, sendo 39,53\% das respostas quanto à observação dos docentes e $38,12 \%$ as orientações e as discussões com professores do Programa de Pós-graduação.

No estudo de Swain e Stout (2000), os resultados encontrados indicaram que a maior parte da formação é recebida por meio da prática, e menos em relação à formação direta e indireta; uma vez que, o método mais comum na formação docente foi a apresentação de workshops, evidenciado pela participação e envolvimento de mais de um terço dos respondentes em dois ou três workshops durante o curso. Esses resultados não corroboram com os encontrados com este estudo, uma vez que na formação prática um número expressivo de respondentes não participou dos métodos estudados.

\subsubsection{Formação pela Instituição de Ensino Superior}

Com o objetivo de identificar se há formação para a docência nas IES foi solicitado aos respondentes que marcassem quais métodos foram utilizados em suas formações, caso tenham participado de alguma atividade voltada para a docência desenvolvida pela IES na qual lecionam. Os respondentes deveriam apontar os métodos utilizados em ordem de importância em suas percepções (Tabela 3).

Tabela 3. Métodos de formação pela IES

\begin{tabular}{lcccccc}
\hline & $\mathbf{1}$ & $\mathbf{2}$ & $\mathbf{3}$ & $\mathbf{4}$ & $\mathbf{5}$ & Não utilizado \\
\hline Workshop interno & 85 & 57 & 31 & 29 & 17 & 106 \\
Workshop externo & 26 & 25 & 33 & 28 & 29 & 184 \\
Simpósio interno & 49 & 64 & 47 & 33 & 20 & 112 \\
Simpósio externo & 23 & 25 & 29 & 34 & 37 & 177 \\
Grupos discussão & 99 & 47 & 42 & 17 & 36 & 84 \\
\hline
\end{tabular}

Fonte: dados da pesquisa.

A maioria dos respondentes apontaram que as IES não utilizam os métodos sugeridos nesse estudo na formação de seus professores, com exceção dos grupos de discussão. No estudo de Swain e Stout (2000), os resultados apontaram que workshop interno é o método mais utilizado pelas IES nos EUA, para apoiar a formação dos professores recém-contratados. Assim ressalta-se a importância da IES na formação continuada dos docentes do ensino superior, uma vez que conforme Rivas, Conte e Aguilar (2007) é papel da IES fornecê-la por ser considerado o ambiente propício para a qualificação, não somente daqueles que nela estudam (alunos), mas também para os que nela ensinam (professores).

Quanto a efetividade da formação proporcionada pela IES onde lecionam, foi questionado aos respondentes se eles se sentem preparados para suas atividades de ensino, a partir dos métodos de formação utilizados pela IES. O Gráfico 2 ilustra os resultados. 


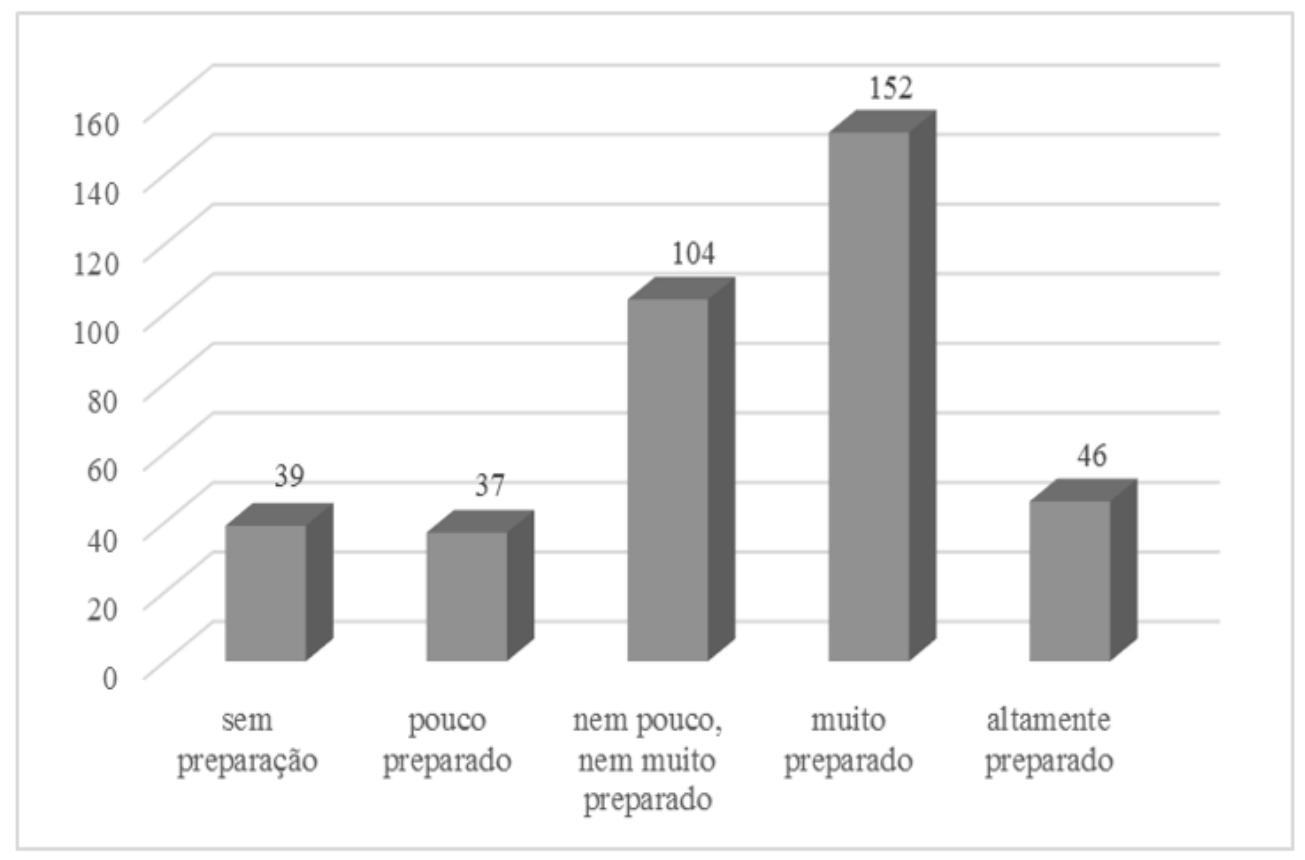

Gráfico 2. Nível de preparação para a docência na IES

Fonte: dados da pesquisa.

Em relação à formação prática proporcionada pela IES, os respondentes foram questionados quanto ao número de: (1) disciplinas que ministram anualmente; (2) workshops ou outros tipos de apresentações que realizam anualmente; e (3) atividades proporcionadas pela IES, com enfoque na formação para a docência (Tabela 4).

Tabela 4. Métodos de formação prática proporcionada pela IES

\begin{tabular}{|c|c|c|c|c|c|c|c|}
\hline & $\mathbf{0}$ & 1 & 2 & 3 & 4 & 5 & +6 \\
\hline Número de disciplinas ministradas, anualmente & 3 & 22 & 77 & 108 & 80 & 30 & 105 \\
\hline $\begin{array}{l}\text { Número de workshops e outras apresentações } \\
\text { realizadas, anualmente }\end{array}$ & 101 & 68 & 103 & 28 & 29 & 22 & 74 \\
\hline Número de atividades proporcionadas pela IES & 142 & 84 & 44 & 25 & 25 & 32 & 73 \\
\hline
\end{tabular}

Fonte: dados da pesquisa.

A maioria dos respondentes ministra três ou mais disciplinas ao longo do ano, resultado que contrasta com o expressivo número de professores que não realizam workshops ou outras apresentações ao longo do ano. Questionados sobre quão preparados se sentem para as atividades de ensino, a partir da formação prática recebida na IES, 63,9\% respondeu sentir-se muito preparado. Conclui-se que há momentos de formação, porém a partir de outros métodos.

No tocante à formação indireta proporcionada pela IES, entende-se que alguns professores sentem que grande parte da formação docente acontece dentro da IES por meio da observação (assistir a aula de outros professores, por exemplo) ou por meio de orientações sobre o assunto. Foi questionado aos respondentes (1) quão contribuiu observar outros professores, na IES em que leciona (caso tenham observado); e (2) quão contribuiu as orientações e as discussões com o colegiado e outros professores, ambos para a formação docente. Para as duas perguntas, a maioria das respostas obtidas apontou que essas ações contribuíram para a formação docente, sendo $31,21 \%$ das respostas quanto à observação dos docentes e 37,04\% no que tange as orientações e as discussões no colegiado e com outros professores.

O resultado corrobora com Slomski (2009), no qual demonstrou que a experiência dos pares vem estruturando e dando sentido à prática docente dos professores de Contabilidade no Brasil. Entretanto, diverge do encontrado por Swain e Stout (2000) com recém-doutores nos EUA, os quais relatam que, aproximadamente, $60 \%$ do total da formação recebida na IES é o resultado da experiência prática, e não de formação indireta. 


\subsubsection{Formação por interesse próprio}

Para identificar se os professores buscam formação para suas atividades de ensino, por interesse próprio, foi solicitado que marcassem quais métodos eles utilizaram para tal. Além disso, os respondentes deveriam assinalar os métodos utilizados em ordem de importância em suas percepções (Tabela 5).

Tabela 5. Métodos de formação individuais

\begin{tabular}{lcccccc}
\hline & $\mathbf{1}$ & $\mathbf{2}$ & $\mathbf{3}$ & $\mathbf{4}$ & $\mathbf{5}$ & Não utilizado \\
\hline Leitura de artigos & 228 & 83 & 29 & 31 & 54 & 0 \\
Leitura de livros & 145 & 119 & 83 & 29 & 46 & 3 \\
Escrita de artigos & 96 & 99 & 128 & 45 & 37 & 20 \\
Escrita de livros & 38 & 37 & 33 & 72 & 45 & 200 \\
Outros & 58 & 31 & 27 & 70 & 68 & 171 \\
\hline
\end{tabular}

Fonte: dados da pesquisa.

Todos os métodos sugeridos como possíveis de auxiliar na formação para a docência foram utilizados, sendo as leituras de artigos e livros os mais recorrentes, e apontados como mais importantes para o processo de formação. O resultado corrobora com o encontrado por Swain e Stout (2000), uma vez que de forma geral, os recém-doutores norte-americanos assinalaram despender cerca de $60 \%$ do seu esforço total na leitura de artigos e livros com foco no ensino. Apontam que aproximadamente 19\% dos entrevistados escrevem artigos ou, em alguns casos, escrevem livros relacionados ao ensino, como forma de aperfeiçoamento pessoal, bem como utilizam outros métodos, tais como refletir sobre auto desempenho e acessar materiais na internet.

Outros métodos foram citados pelos respondentes do presente estudo, como: vídeos assistidos na internet de aulas dos temas da disciplina e de didática de ensino; leitura de materiais técnicos; disciplinas e curso de especialização em educação; revisão de artigos; participação em eventos; discussão e troca de experiências com colegas de instituição; preparação de material didático; observação; casos práticos; filmes; diálogos com profissionais da área de educação; grupos de estudo; elaboração de dissertação e tese sobre assuntos diretamente relacionados com a formação e atuação do professor no ensino superior, modalidades didáticas, currículo, processo educacional e formação dos estudantes; seminários e, projetos de extensão.

\subsection{Teste de Wilcoxon}

Com o objetivo de comparar a percepção dos respondentes quanto à responsabilidade de cada espaço formativo na formação para a docência e o real efeito desses espaços na formação dos docentes, utilizou-se do Teste de Wilcoxon, o qual compara duas médias populacionais a partir de amostras emparelhadas e leva em consideração a magnitude da diferença dentro dos pares (FÁVERO, BELFIORE, SILVA \& CHAN, 2009).

Descartou-se a utilização do teste de Kruskal-Wallis e o teste de Friedman, pois esses comparam três médias entre si e não duas, como proposto nesse estudo (responsabilidade e formação real) para cada uma das fontes: IES, pós-graduação e interesse próprio, separadamente. Com base no nível de significância de 5\%, foram formuladas as seguintes hipóteses:

$\mathrm{H}_{0}$ : Não há diferença significativa entre a responsabilidade da fonte (Pós-graduação, IES e interesse próprio) e a contribuição dessa na formação para a docência.

$\mathrm{H}_{1}$ : Há diferença significativa entre a responsabilidade da fonte (Pós-graduação, IES e interesse próprio) e a contribuição dessa na formação para a docência.

A responsabilidade pela formação para a docência, tanto do Programa de Pós-graduação (PG) quanto das IES é maior do que a formação proporcionada por essas fontes. E que, a formação por interesse próprio (IP) vem 
suprindo a formação, que não está sendo proporcionada de forma adequada pelas outras duas fontes de formação (Tabela 6).

Tabela 6. Postos atribuídos à cada fonte de formação para a docência

\begin{tabular}{lccccccccc}
\hline $\begin{array}{c}\text { Responsabilidade - } \\
\text { efeito }\end{array}$ & \multicolumn{3}{c}{ N } & & & Média & & \multicolumn{2}{c}{ Soma dos postos } \\
\hline & PG & IES & IP & PG & IES & IP & PG & IES & IP \\
Postos negativos & $107^{\mathrm{a}}$ & $53^{\mathrm{a}}$ & $196^{\mathrm{a}}$ & 111,60 & 97,35 & 138,14 & 11941,50 & 5159,50 \\
Postos positivos & $140^{\mathrm{b}}$ & $195^{\mathrm{b}}$ & $55^{\mathrm{b}}$ & 133,48 & 131,88 & 82,73 & 18686,50 & 25716,50 \\
Empates & $124^{\mathrm{c}}$ & $123^{\mathrm{c}}$ & $120^{\mathrm{c}}$ & & & & & \\
Total & 371 & 371 & 371 & & & & & \\
\hline
\end{tabular}

Fonte: dados da pesquisa.

Nota: a. Responsabilidade $<$ efeito /; b. Responsabilidade $>$ efeito; $\mathrm{c}$. Responsabilidade $=$ efeito

Estes resultados são ratificados pelos valores encontrados no p-value de cada teste, uma vez que para os três testes o p-value $<0,05$, o que faz com que a hipótese nula seja rejeitada, ou seja, há uma diferença significativa na responsabilidade que a Pós-graduação ( $p$-value $<0,002$ ), a IES (p-value $<0,000$ ) e a busca por interesse pessoal ( $p$-value $<0,000)$ deveriam ter na formação para a docência e o efeito de cada fonte na formação obtida pelo respondente.

As conclusões de Swain e Stout (2000) corrobora com o resultado exposto, os quais afirmam que a maior parte dos esforços para desenvolver as competências didático-pedagógicas na formação dos recém-doutores em contabilidade nos EUA baseia-se no esforço do indivíduo a partir de interesse próprio.

Tal colocação pode ser comprovada com a análise das médias das respostas atribuídas pelos respondentes aos três espaços formativos nos dois aspectos analisados nesse tópico: (1) o efeito de cada espaço formativo na formação para a docência; e (2) a responsabilidade que cada um dos três domínios deveriam ter na formação docente, conforme demonstrado no Gráfico 3.

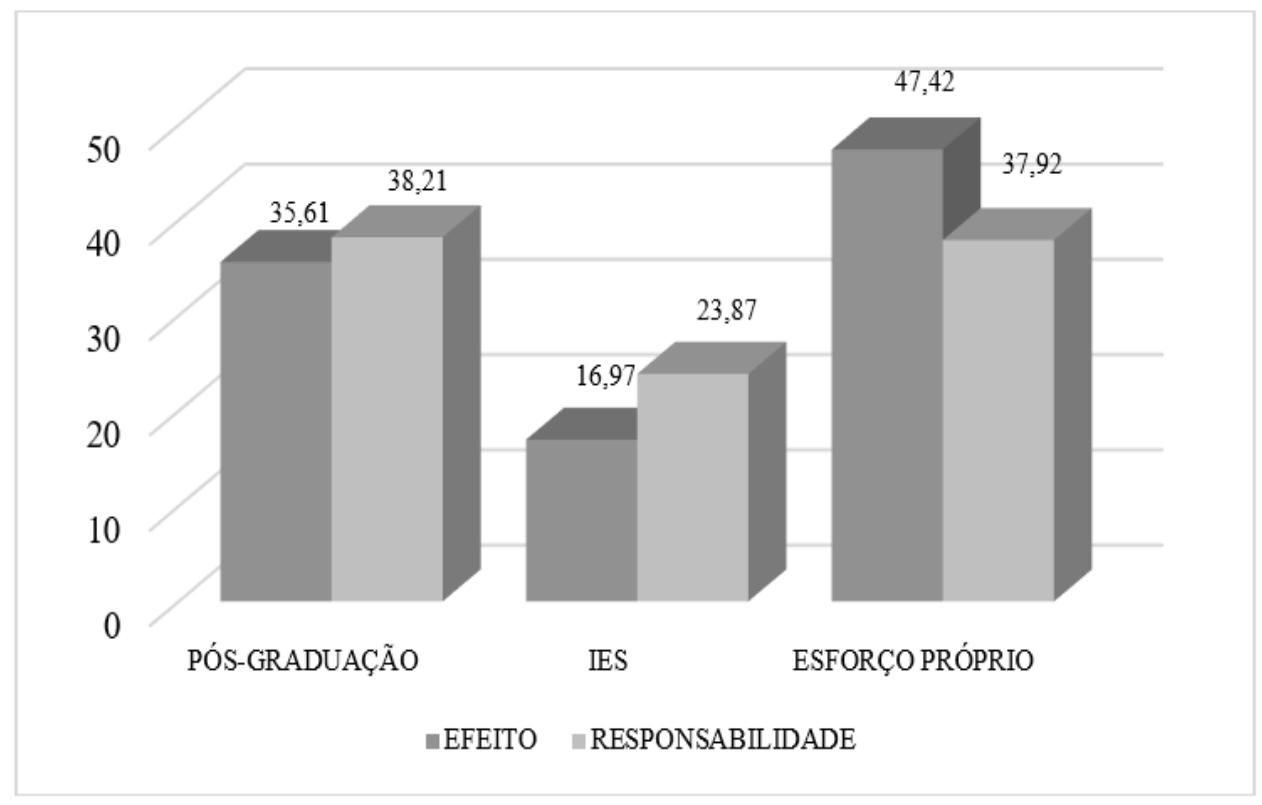

Gráfico 3. Média das respostas

Fonte: dados da pesquisa

De acordo com a primeira questão, a formação obtida por esforço individual possui maior efeito, correspondendo à $47,42 \%$, seguida pela Pós-graduação $(35,61 \%)$ e, por fim, a IES com $16,97 \%$. Na segunda 
questão, foi atribuído que a Pós-graduação deveria ser a maior responsável pela formação para a docência $(38,21 \%)$, seguida pelo esforço individual $(37,92 \%)$, e por fim, pela IES $(23,87 \%)$.

Dessa forma, conclui-se que a Pós-graduação e as IES deveriam comprometer-se mais com a formação continuada dos docentes e futuros docentes de contabilidade, uma vez que a IES, conforme, Rivas, Conte e Aguilar (2007) é considerada o ambiente propício para a qualificação, e como determinada a LDB, que a preparação para o exercício da docência superior far-se-á, prioritariamente, nos cursos de Pós-graduação.

\section{CONSIDERAÇÕES FINAIS}

O objetivo do presente estudo foi analisar a percepção dos docentes, mestres e doutores, em Contabilidade no Brasil a respeito da sua formação a partir dos possíveis métodos utilizados por três espaços formativos: Pósgraduação, IES onde atua como docente e a partir da busca de formação por interesse próprio. Os principais resultados encontrados apontam que a formação para a docência, proporcionada pelo Programa de Pós-graduação, ocorre, em sua maioria, a partir de disciplinas, corroborando com os métodos identificados por Lapini (2012).

Quanto à responsabilidade pela formação e a real formação proporcionada, verificou-se que a responsabilidade da Pós-graduação é maior que a formação real proporcionada. O resultado vai ao encontro de outros estudos, os quais indicam que os programas de Pós-graduação em contabilidade continuam com foco na formação de pesquisadores, não sendo a formação docente suficientemente oferecida nos cursos de mestrado e doutorado da área (ANDERE \& ARAUJO, 2008; LAPINI, 2012; MIRANDA, 2010; NGANGA, BOTINHA, MIRANDA \& LEAL, 2016). Dessa forma, infere-se que a participação da Pós-graduação na formação dos docentes de contabilidade ainda é elementar.

Quanto a participação das IES na formação dos docentes, infere-se que essa formação ocorre de forma tímida, uma vez que nenhum método apontado no presente estudo é utilizado na formação dos professores do ensino superior, com exceção dos grupos de discussão, os quais dizem respeito a troca de experiências em discussões informais com os pares, e não provenientes de cursos de formação formalizados e sistematizados proporcionados pela instituição de ensino, como sua política de formação. Essa inferência baseia-se nas ações pontuais empreendidas por algumas IES com o objetivo de auxiliar na formação do seu corpo docente.

No quesito formação a partir de interesse próprio, verificou-se que todos os métodos sugeridos foram utilizados, e que, a formação por interesse próprio vem suprindo a formação, que não vem sendo proporcionada de forma adequada pelas outras duas fontes de formação.

Como contribuições, reflete-se quão, de fato, os docentes de contabilidade são altamente formados para o exercício da docência, como apontado nos resultados, uma vez que fica evidente que tanto os Programas de Pósgraduação quanto às IES possuem mais responsabilidade sobre a formação dos docentes, do que a real formação que os proporcionam. Outro ponto de reflexão é o quanto os programas de pós-graduação estão preparando os seus docentes para o exercício da profissão.

O estudo considerou a percepção de docentes, mestres e doutores em Contabilidade titulados no Brasil, desconsiderando outros agentes em seu processo formativo, como coordenadores de Pós-graduação e dirigentes das IES os quais podem gerar informações relevantes para triangulações, a partir de suas percepções. Pesquisas futuras abordando estes outros agentes pode ser promissora para novas discussões. Vislumbra-se estudos com abordagem qualitativa abordando do ponto de vista comportamental, ou seja, o docente que se considera altamente formado para desempenhar suas atividades docentes, de forma que desenvolve com qualidade o processo de ensino-aprendizagem.

\section{REFERÊNCIAS}

ALMEIDA, M. I.; PIMENTA, S. G. (2014). Pedagogia universitária - valorizando o ensino e a docência na universidade. Revista Portuguesa de Educação, v. 27, n. 2, p. 7-31.

ANDERE, M. A.; ARAUJO, A. M. P. de. (2008). Aspectos da formação do professor de ensino superior de ciências 
contábeis: uma análise dos programas de Pós-graduação. Revista Contabilidade \& Finanças, v. 19, n. 48, p. 91-102.

ARAUJO, A. M. P.; MELLO, R. R. (2014). What is the training of the accounting professor in Brazil? Creative Education, v.5, p. 886-899.

BAQUEIRO, J. F. (2007). O docente do ensino superior: formação, desafios e perspectivas. In: IX Congresso Estadual Paulista sobre formação de educadores, 2007, SP. Anais... SP, Congresso Estadual Paulista sobre formação de educadores.

BOYLE, D. M.; CARPENTER, B. W.; HERMANSON, D. R.; MERO, N. P. (2015). Examining the perceptions of professionally oriented accounting faculty. Journal of Accounting Education, v. 33, p. 1-15.

BRIGHTMAN, H. J.; NARGUNDKAR, S. (2013). Implementing comprehensive teacher training in business doctoral programs. Decision Sciences Journal of Innovative Education, v. 11, n. 4, p. 297-304.

DILLMAN, D. A. (2007). Mail and internet surveys. New York: John Wiley Professional.

FÁVERO, L. P.; BELFIORE, P.; SILVA, F. L.; CHAN, B. L. (2009). Análise de dados: Modelagem multivariada para tomada de decisões. RJ: Elsevier.

GIL, A. C. (2006). Didática do Ensino Superior. São Paulo: Atlas.

HUBERMAN. M. (2000). O ciclo de vida profissional dos professores. In: Vida de professores. Porto: Porto.

LAFFIN, M. A formação continuada do professor do ensino superior e a constituição do tornar-se professor. In: Cassiani, S. (Org.). Lugares, sujeitos e conhecimentos: a prática docente universitária. Florianopolis: Ed. UFSC, 2008, v. 1, p. 11-15.

LAFFIN, M. Currículo e trabalho docente no curso de Ciências Contábeis. Revista de Contabilidade da UFBA, v. 6, n. 3, p. 66-77, 2012.

LAPINI, V. (2012). Panorama da formação do professor em Ciências Contábeis pelos cursos stricto sensu no Brasil. 2012. 76f. Dissertação (Mestrado em Ciências), Universidade de SP, Ribeirão Preto.

MARSHALL, P. D., DOMBROWSKI, R., GARNER, M., e SMITH, K. (2010). The Accounting Education Gap. The CPA Journal, v. 80, n. 6, p. 06-10.

MELO, M. M. O.; CORDEIRO, T. S. C. (2008). Formação Continuada - Uma Construção Epistemológica e Pedagógica da/ e na Prática Docente Universitária no Contexto da UFPE. In: CORDEIRO, T. S. C.; MELO, M. M. O. (Orgs.). Formação Pedagógica e Docência do Professor Universitário: Um Debate em Construção. Recife: Ed. Universitária da UFPE.

MIRANDA, G. J. (2010). Docência universitária: uma análise das disciplinas na área da formação pedagógica oferecidas pelos programas de Pós-graduação stricto sensu em Ciências Contábeis. Revista de Educação e Pesquisa em Contabilidade, v. 4, n. 2, p. 81-98.

MIRANDA, G. J.; CASA NOVA, S. P. D. C.; CORNACCHIONE JÚNIOR, E. B. (2014). Uma aplicação da técnica delphi no mapeamento das dimensões das qualificações docentes na área contábil. Revista de Educação e Pesquisa em Contabilidade, v.8, n.2, p.142-158.

NGANGA, C. S. N.; BOTINHA, R. A.; MIRANDA, G. J.; LEAL, E. A. (2016). Mestres e doutores em contabilidade no Brasil: uma análise dos componentes pedagógicos de sua formação inicial. Revista Iberoamericana sobre Calidad, Eficacia y Cambio em Educación, v. 16, n. 1, p. 83-99.

NGANGA, C. S. N.; BOTINHA, R. A.; MIRANDA, G. J.; LEAL, E. A. (2014). Mestres e doutores em sala de aula: eles estão sendo formados para ensinar? In: VIII Congresso Anpcont, 2014, RJ. Anais... RJ, Congresso Anpcont.

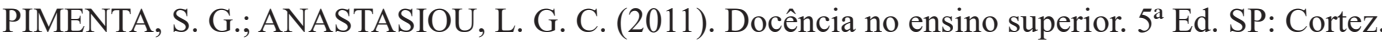

RIVAS, N. P. P.; CONTE, K. M.; AGUILAR, G. M. (2007). Novos espaços formativos na universidade: desafios e perspectivas para a docência superior. In: IX Congresso Estadual Paulista sobre formação de educadores, 2007, SP. Anais... SP, Congresso Estadual Paulista sobre formação de educadores.

SHULMAN, L. S. (1987). Knowledge and teaching: foundations of the new reform. Harvard Educational Review, v. 57, n. 1 , p. $1-22$.

SLOMSKI, V. G. (2007). Saberes e competências do Professor Universitário:contribuições para o estudo da Prática 
Pedagógica do Professor de Ciências Contábeis do Brasil. Revista de Contabilidade e Organizações, v. 1, p. 86-106.

SLOMSKI, V. G. (2009). Saberes que fundamentam a prática pedagógica dos professores de ciências contábeis. Revista Brasileira de Contabilidade, n. 178-180, p. 119-140.

SLOMSKI, V. G., LAMES, E. R., MEGLIORINI, E., LAMES, L. C. J. (2013). Saberes da docência que fundamentam a prática pedagógica do professor que ministra a disciplina de gestão de custos em um curso de ciências contábeis. Revista Universo Contábil, v. 9, n. 4, p 71-89.

SOUZA, G. B. (2013). Formação continuada de professores do ensino superior: composição organizativa da identidade docente. 2013. 154f. Dissertação (Mestrado em Educação), Universidade Federal de Pernambuco, Recife.

SWAIN, M. R.; STOUT, D. E. (2000). Survey evidence of teacher development based on AECC recommendations. Journal of Accounting Education, v. 18, p. 99 - 113.

TARDIF, M. (2012). Saberes docentes e formação profissional. 13 ed. Petrópolis-RJ: Editora Vozes.

TARDIF, M.; RAYMOND, D. (2000). Saberes, tempo e aprendizagem do trabalho no magistério. Educação \& Sociedade, v. 21, n. 73, p. 209-244.

VENDRUSCOLO, M. I.; BEHAR, P. A. (2014). Accounting Professor Competencies: Identification of Educational Elements in the Education Process of Accounting Professors in Distance Education. In: Key Competencies in ICT and Informatics: implications and issues for education professionals and management. p. 94-105. Editora: Sspringer. 